\title{
Methodology in the Large: Modeling All There Is
}

\author{
Brian R. Gaines \\ Department of Industrial Engineering \\ University of Toronto, Ontario, Canada M5S 1A4
}

\begin{abstract}
The human mind has been inventive of a multitude of methodologies to explain observed phenomena, predict possible worlds, determine which ones should be made real, and bring this about. In recent years the computer has enhanced our capability to project the detail of possible worlds and widen our vision of the consequences of our actions. We bring together the physical and human variables, political and economic policies, and constraints of resources, and expect increasing model realism. With advances in computer technology we have begun to see the possibility of large-scale methodologies that eventually cope with all there is. This paper is concerned with placing our endeavours for model realism in the socio-economic sphere within the much broader context of humankind's overall endeavours for model realism. It expresses the main philosophical problems underlying our situation in a parable, and then goes on to sketch some of the solutions proposed for them in the past. It concludes with a model for the role of the computer as a vehicle to explore Popper's World 3, and the use of his notion of three worlds to express the different styles and motivations of schools of modeling and concepts of realism.

“...in the three decades between now and the twenty-first century, millions of ordinary, psychologically normal people will face an abrupt collision with the future.” (Toffler, 1970, p.18)

"Man not only exists but knows that he exists. In full awareness he studies his world and changes it to suit his purposes. He has learned how to interfere with 'natural causation', insofar as this is merely the unconscious repetition of immutable similars. He is not merely cognizable as extant, but himself freely decides what shall exist. Man is mind, and the situation of man as man is a mental situation." (Jaspers, 1931, p.11)

"The quantification of nature, which led to its explication in terms of mathematical structures, separated reality from all inherent ends and, consequently, separated the true from the good, science from ethics." (Marcuse, 1964, p.122)
\end{abstract}

\section{INTRODUCTION}

In April 1982 a conference took place at Bad Honnef in Germany concerned with Model Realism. It was remarkable because the organizer, Horst Wedde, attempted to force comparability between the different approaches to modeling proposed by asking all participants to illustrate their methodologies applied to one of three well-defined case histories. The papers and commentaries given at the conference are available in the book Adequate Modeling of Systems (Wedde, 1983). This paper is based on an evening address given by the author in a wine cellar as part of the lighter side of the conference. It attempts to put our endeavours to create increasingly real global models in the wider perspective of man's search for meaning, illustrating the general points made by quotations from the book Groping in the Dark (Meadows, Richardson and Bruckmann, 1982) which is based on comparisons of seven global models at the Sixth IIASA Symposium on Global Modelling.

Throughout recorded history the human mind has been inventive of a multitude of descriptive and prescriptive methodologies to explain observed phenomena, predict possible worlds, determine which ones should be made real, and bring this about. Until this decade all such methodologies suffered from the intrinsic tunnel vision of human computation which can see relatively few of the consequences of action. What we modeled and simulated were microworlds, often carved out from reality in the laboratory, and whilst this enabled great leaps

Presented as the First Drachenfels Lecture in the Burgerstubchen at the International Working Conference on Model Realism, Bonn, Federal Republic of Germany, April 20-23, 1982. 
forward to be made in the technologies of the artificial, it usually neglected the natural or subsumed it only by destroying it.

We can comprehend much of our technological universe only because it is designed to be comprehensible, a world of simplicity in a universe of chaos. The powerful models of linear systems theory work not because they reflect reality but rather because we have built worlds of mechanical and electronic systems which are linear, and hence can be modeled, designed and controlled. Outside technologically created reality linear systems theory has far less to offer in modeling the worlds of nature.

In recent years the computer has enhanced our capability to project the detail of possible worlds and widen our vision of the consequences of our actions. We bring together the physical and human variables, political and economic policies, and constraints of resources, and expect increasing model realism. With the ever-increasing pace of advances in computer technology we have begun to see the possibility of large-scale methodologies that eventually cope with all there is. One can envision a next generation of global models that encompass broad socio-economic scenarios such as Kondratiev's (Mensch, 1975) and Toffler's (1980) waves, extending the simplified and aggregated global models of today (Meadows et al., 1982) to a level of economic, psychological and physical detail at as great a depth as required.

However, the momentum of our new intellectual technologies should not blind us to the foundational weaknesses of our endeavours. A major lesson of all the global models of today is that we are the creators of reality, not its discoverers, and the presuppositions that we make increasingly determine the worlds that we find ourselves in. The utopias of yesterday (Goodwin, 1978) may seem foolish in their naive hopes but our computational scenarios of tomorrow, for all their quantitative detail, are only computing the consequences of the assumptions we have made according to the rules we have built in.

This presentation is concerned with placing our endeavours for model realism within the socioeconomic sphere within the much broader context of humankind's endeavours for model realism in general. One conclusion of the IIASA Symposium on Global Modelling was:

"The methodological problems of global modellers are common to all social-system modellers." (Meadows et al., 1982, p.269)

One conclusion to be drawn form this paper will be that the methodological problems of global modelers are common to all modelers, noting that the most outstanding characteristic of humankind is that we all are, and always will be, modelers (Shaw, 1980). We have also always been concerned with modeling all there is but it is only now, as we use machines with greater capacity than ourselves, that we can really appreciate that when, or if, we do this we may not have the capacity to understand what we have done let alone check its validity; whatever that means.

The next section expresses the main philosophical problems underlying our situation in a parable, and then goes on to sketch some of the solutions proposed for them in the past. 


\section{PLURALITIES OF REALITIES}

“...though all our knowledge begins with experience, it by no means follows, that all arises out of experience. For, on the contrary, it is quite possible that our empirical knowledge is a compound of that which we receive through impressions, and that which the faculty of cognition supplies from itself" (Kant, $1781, p .1)$

"Law is the Reflection of Appearance into identity with itself." (Hegel, 1816, v.II, p.132)

"The expectation of my death as a definitive departure (from the life world) also arises out of my existence in the intersubjective world. Others become older, die, and the world continues on (and I in it)...I become older; thus I know that I will die and I know that the world will continue." (Schutz and Luckmann, 1973, p.47)

What is the method by which we can model reality, or, at least, realistically model? For an individual the world presents few philosophical problems. He, she, or it, can follow his, her, or it's own process of knowledge acquisition. Each moment brings a little more information and a closer glimpse of reality. The summit of knowledge, to know all, is like a mountain peak; perhaps never to be climbed but the path through the foothills is inexorable and obvious.

Let us assume that the individual is myself happily meandering through the paths of experience, when I suddenly become aware of you. You, that is, not just as part of the scenery and the experience, but you as an analog of me. I make the conceptual leap that identifies you as having processes of knowledge comparable with mine. Now I begin to have problems. Your paths through the foothills are different. Are they better or worse than mine? If there are two of us, why not more? Suddenly I notice the others, me, you and them, all taking different directions.

After a while I realize that people are born and die, and that I also was born and will die. Will I reach the summit before I die? If I do what will I do with my knowledge of reality? I am now thankful for the others because I can pass the knowledge on. Reality will survive me. I also realize how much I am relying now on the experience and knowledge of others. Much of my own knowledge is now not from my own experience but from the experience of others. The search for reality has become a communal endeavour and reality itself, given the death of individuals, has become meaningful only in a communal context.

All these realizations have taken place within a framework of a common quest undertaken through a common approach. Then I notice that one of the others is not only taking a different direction but is exploring the world using entirely different methods. He floats by in a hot air balloon. Will he reach the mountain top and see the whole of reality before us?

At some point in my pondering I may discover one of the fundamental laws of reality, that things may be enumerated in three different ways; there is zero, one, or infinity of everything. There was one of me, and then I found you, so there must be an infinite number of epistemological beings. There could also be none of us. That is an awesome possibility. What is left if we all go, and what happens to reality? There was one method of discovering reality, and then this fellow came by in a balloon, so now there are two, and hence an infinity. Suppose there are none. The mountain summit cannot be reached and our effort is meaningless. What then? 
But what of reality itself? If there are many searchers and many methods of searching then may not there be many realities? And sure enough, as I watch, the sun comes over the mountain and I glimpse many more mountain peaks in the distance.

This parable of the wanderers in the foothills of the mountains captures most of the philosophical problems of reality. None of them have ever been solved. We can be confident that none of them ever will be. In recent years Niklas Luhmann has put the dilemmas that this entails in system theoretic terms and used them as an underlying dialectic from which to derive the operation of society:

"The world is overwhelmingly complex for every kind of real system... Its possibilities exceed those to which the system has the capacity to respond. A system locates itself in a selectively constituted 'environment' and will disintegrate in the case of disjunction between environment and 'world'. Human beings, however, and they alone, are conscious of the world's complexity and therefore of the possibility of selecting their environment -- something which poses fundamental questions of self-preservation. Man has the capacity to comprehend the world, can see alternatives, possibilities, can realize his own ignorance, and can perceive himself as one who must make decisions." (Luhmann, 1979, p.6)

He also emphasizes the problems created for the modeler of there being other modelers:

"we invoke a whole new dimension of complexity: the subjective 'I-ness' of other human beings which we experience (perceive) and understand. Since other people have their own first-hand access to the world and can experience things differently they may consequently be a source of profound insecurity for me." (Luhmann, 1979, p.6)

This "sense of insecurity" was profoundly expressed some 2,300 years ago by a discussant of modeling problems who, in his simile of the man who went outside the cave and saw the reality behind the shadows on the wall, remarked about the others in the cave:

"if anyone tried to release them and lead them up, they would kill him" (Plato, 1958, orig, c.380 BC)

Some of the "friendly remarks" by commentators at the modeling conferences may be taken as the modern, more civilized, version of such interaction.

It is not easy to accept the insecurity and apply it to ones own model of the world. We prefer to stick to our "known" models and not regard them as assumptions:

"Many plans, programs and agreements, particularly complex international ones, are based on assumptions about the world that are either mutually inconsistent or inconsistent with physical reality. Much time and effort is spent designing and debating policies that are, in fact, simply impossible." (Meadows et al., 1982, p.16)

The law of reality stated above will be used as the theme of the next three sections, showing how the three ways of enumerating methods of reality each have their major proponents, strengths and weaknesses.

\section{ZERO: THERE IS NO METHOD OF REALITY}

“...there is nothing in any object consider'd in itself, which can afford us a reason for drawing a conclusion beyond it” (Hume, 1739, p.139)

"Scepticism is not irrefutable, but obviously nonsensical when it tries to raise doubts where no questions can be asked." (Wittgenstein, 1972, sect.6.51, orig.1921)

"I found Hume's refutation of inductive inference clear and conclusive." (Popper, 1963, Ch.1 IV) 
That there is no method of reality has been the sceptical position throughout the ages, leading in its most extreme forms to total nihilism. The first clear statement of nihilist scepticism is attributed to Gorgias, but probably pre-dated him and has been many times re-discovered. Gorgias held:
(1) Nothing exists;
(2) Even if something did exist it could not be known;
(3) Even if it were known this knowledge could not be communicated.

This is a particularly attractive argument sequence because it can so easily be extended:

(4) Even it it were communicated this communication could not be understood;

(5) Even if it were understood this understanding could not be utilized;

(6) Even if it were utilized this utilization could not be beneficial.

and so on!

The clearest, and most convincing, statement of the sceptical position is that of the Roman philosopher Sextus Empiricus in his Outlines of Pyrrhonism (Sextus Empiricus, 1933, orig.c.300BC), who discusses a form of non-nihilist scepticism originating with Pyrrho of Elis but substantially developed by many subsequent philosophers into a methodology of thought and decision based on the suspension of judgement. Pyrrhonists based their suspension on some ten rules which seem fresh and cogent today, e.g.: I suspend judgement; I determine nothing; to every argument an equal argument is opposed; regression ad infinitum is necessary in any form of explanation not based on dogmatism.

It is easy to dismiss the ZERO hypothesis as being absurd and offensive to commonsense. Wittgenstein countered Hume's doubts about information from the past relating to events in the future, noting that the pattern of reasoning involved was prior to that used by Hume and transcended it:

"If anyone said that information about the past could not convince him that something would happen in the future, I should not understand him.” (Wittgenstein, 1953, sect.481, orig.1945)

However, Hume, although often vilified, has never been answered in his own terms:

"To refute him has been, ever since he wrote, a favourite pastime among metaphysicians. For my part, I find none of their refutations convincing; nevertheless, I cannot but hope that something less sceptical than Hume's system may be discoverable." (Russell, 1946, Ch.XVII)

and new defences of the sceptical position are still being published (Unger, 1975).

The sceptical position itself seems to offer only disillusionment, that we:

"sit down in forlorn Scepticism" because we have departed "from sense and instinct to follow the light of a superior Principle" and "a thousand scruples spring up in our minds concerning those things which before we seemed fully to comprehend” (Berkeley, 1710, p.45)

and Russell terms Hume's scepticism:

"the bankruptcy of eighteenth century reasonableness" (Russell, 1946, p.645)

It is, however, this same dissolution of illusion, the ripping of the veil of maya, the dynamic bankruptcy that leaves us with all false currency spent and only new beginnings before us, that is the vital force of scepticism as a genesis for knowledge. This dialectical significance of 
scepticism shows up in Popper's reply to Hume, based not on answer but acceptance. He reestablishes an empiricist epistemology on the possibility of laws being falsified but accepts the Humean position that they cannot be verified:

"we must regard all laws or theories as hypothetical or conjectural; that is, as guesses" (Popper, 1972, Ch.1 6)

Descartes (1964, orig.1637) rediscovered scepticism as the tool of ultimate doubt that removes all but the essence of reality. Sartre (1943) continues in the Cartesian tradition with his emphasis on néantisation as the force behind the transcendent upsurge of consciousness that makes knowledge possible. As Catalano remarks in his commentary on L'Etre et Néant:

"when I ask, 'What is a tree?' I remove, or negate, the tree from the totality of nature in order to question it as a distinct entity. Also, when I question the nature of a tree, I must have a certain 'distance' within myself that allows the tree to reveal itself to me. It is this 'nothingness' within myself that both separates the tree as this thing within nature and allows me to be aware of the tree. It is this break with a causal series, which would tie being in with being in a fullness of being, that is the nothingness within man and the source of nothingness within the world." (Catalano, 1974, p.66)

This line of argument could be developed and exemplified further but enough has been said here to illustrate the role of what Margaret Wiley (1966) has termed Creative Scepticism and illustrates with literary examples as well as those from Eastern and Western philosophy. It is not the nihilist scepticism of Gorgias that became the dogmatic scepticism of many later philosphers. This is self-defeating because the positive affirmation of non-existence is itself subject to scepticism. It is rather the Pyrrhonism propounded by Sextus Empiricus that suspends belief, searches out opposites, quests for truth through balance rather than dogma, and holds the manner of quest itself subject to doubt at the very moment that truth appears to have been found.

In practical modeling the ZERO hypothesis has a key role in allowing us to break out of selfconsistent systems that somehow do not work or, more insidiously, that do work but not as well as they could. In general it is the tried and trusted rule which generates the biggest explosion of novelty under the fuse of doubt. It is the strong point of an argument that yields most under a sceptical attack. We should doubt that which we find most efficacious, and disbelieve that which seems most obvious.

In this day and age Kuhn's (Kuhn, 1962) normal science proceeds at such a rapid pace that the consequences of an argument, its verification through a wealth of exemplars, and its practical utilization through implementation in systems, are as good as over once begun. We consolidate innovation to form dogma at a pace that allows little scope for contemplative imagination. The circle is no longer open than it is complete again. With the advent of the computer this tendency becomes amplified since computers are generally programmed to be the ultimate dogmatist, propounding incessantly and without variation those dogmas that have been set into them through software. Even the fortuitous processes of evolution cannot be used to break out of such algorithmic dogma (Bremmermann, Rogson and Salaff, 1965). It is active scepticism that must, in Popper's words:

"replace routine more and more by a critical approach" (Popper, 1974)

and somehow we have to find ways to embed it in our reality-modeling systems. 
In the world of global modeling the key role of the active critical scepticism of the Science Policy Research Unit at Sussex is widely acknowledged and has been made a feature of the SARU model development (Meadows et al., 1982, p.66). Donella Meadows notes in relation to the Forrester/Meadows model:

"We would recommend to model sponsors that every model be fully documented and then given to its strongest ideological enemies for testing.” (Meadows et al., 1982, p.131)

\section{ONE: THERE IS ONE CORRECT METHOD OF REALITY}

"When all the Conditions of a Fact are present, it enters into Existence." (Hegel, 1816, v.II, p.105)

"Very good! What has the Absolute Idea and idealism to do with it? Amusing, this 'derivation' of ... existence ...” (Lenin, 1961, p.147, orig.1914-1916)

The ONE hypothesis has its dynamics and its dangers fully equal to those of ZERO. The great significance of existence hypotheses and existence proofs and the key role they play in mathematics is always something of a surprise to those who meet it for the first time. To go from knowing nothing about $\mathrm{A}$ to knowing that A exists may seem a very small step on the path to those who wish to know what A actually is. However, an existence proof is often sufficient in its own right to lead to a derivation of the properties of $\mathrm{A}$ and even a construction of $\mathrm{A}$ itself. The line of argument involved is of the form:
(i) A exists.
(ii) Any A must P.
(iii) $B$ does $P$.
(iv) No other entity does $P$.
(v) Hence $B$ is $A$.

It is interesting to note that the obvious temptation to put this into symbolic logic in the form of the classical predicate calculus must be resisted. This is because step (ii) is not adequately captured by the statement:

(ii') $\square A P(A)$

since we have the standard result, $\square A P(A) \quad \square A P(A)$, that is, (ii') pre-supposes (i), whereas (ii) itself is intended to be independent of the truth of (i). We can state that all unicorns have horns without having claimed that a unicorn exists. It is clearly desirable that this pattern of reasoning be adequately formalized, and Schock (1968) has given an exposition of the problems involved and some of the solutions developed.

Returning to the argument sequence stated above, we can see that its significance lies in the fact that given only that $\mathrm{A}$ exists, and that $\mathrm{A}$ has the property $\mathrm{P}$, we may find out under some circumstances precisely what A actually is. Somehow the necessity of existence of A has generated a complete ontology of A. The danger is that a false hypothesis of existence can lead through a weak and obvious property to a strong ontological result. The strength of such fallacious reasoning is that the existence hypothesis itself appears to have little content; certainly too little to be responsible for that of the result derived from it.

The classic example (Gaines, 1980) of the mis-application of the argument above is:

(I) There exists a largest positive integer. 
(II) The square of any integer is greater than or equal to it.

The square of the largest integer cannot be greater than it so that it must be equal to it.

(III) 1 squared equals 1.

(IV) No other positive integer squared equals itself.

(V) Hence the largest positive integer is 1.

Only the first step, (i) the existence hypothesis, is false in this line of argument. From the supposition that a largest positive integer exists we have managed to determine precisely what it must be.

Note also the key role of step (iv). In the example given step (iv) may be proved explicitly. However the ONE hypothesis gives us both existence and unicity without any further requirement for proof; steps (i) and (iv) in the argument are available for free. Essentially, the ONE hypothesis says that if we can find an agreed property that A must have to be termed A, and we can find an actual entity $B$ that has that property, then there is no need to perform any further tests of B to verify that it is A, nor any need to look for alternatives to B to falsify that it is A. Without further activity we may say that B necessarily is A.

The ONE pre-supposition often turns up in modeling literature as an assumption of the existence of a unique optimum solution to a problem, e.g. we will determine the best model of this economy. There may be no such best entity because the decision criterion cannot be uniformly satisfied, and even if there is one it may not be unique. These various possibilities show up as an ambiguity in the use of the word optimum:

Opt1: an optimum solution is one such that no other is better;

Opt2: an optimum solution is one that is better than all others;

Opt3: an optimum solution is one that is better or equal to any other.

The three definitions coincide under conditions of unicity but not necessarily otherwise. To differentiate between them we have to enlarge our vocabulary and call Opt1 admissible (Gaines, 1977) rather than optimum; the non-existence of better solutions may be due to incomparability. Opt 2 would be called a unique optimum, leaving Opt3 as the correct precisiation of optimum (reading correct here as agreed by convention since any of these definitions may be taken as precisifying the colloquial term optimum).

In the control literature lack of appreciation of these distinctions has several times resulted in the publication of extensions to the Pontryagin maximum principle which purports to show that it is applicable to discontinuous decision spaces also. Such forms of discrete maximum principle are however incorrect; the proofs incorporate tacit assumptions of results from the continuous case that do not carry over to the discrete case. One of the most powerful features of continuity is the well-ordering it establishes in solution neighbourhoods, and this is what allows Pontryagin's formulation but no discrete equivalent.

As a further example of the role of unique existence hypotheses in modeling, categorial adjunctions may be seen as arising essentially through the unicity of a pair of reciprocal functors. The Goguen/Arbib/Ehrig behaviour/structure adjunction (Gaines, 1978) encompassing a wide range of system identification schemes is dependent on the existence of a unique structure 
ascribable to an observed behaviour. Attempts to determine a similar adjunction for stochastic systems were doomed to failure because no comparable unique solution was definable. However, the meta-systemic move to define the solution in terms of the admissible space of structures has allowed Ralescu (1979) to express behaviour/structure transformations in the stochastic and fuzzy cases as adjunctions because the admissible space is itself unique.

It is the pre-supposition of ONE that most often leads to fruitless searches for solutions that result in the conclusion that the problem is insufficiently well-defined. What we mean by welldefined seems to be the existence of a unique solution. However, it should be clear that problems can be solved in some sense without necessitating unicity of solution, and thus that some problems may be solved even though they are ill-defined. Indeed, requiring them to be precisified to a state of well-definition in this sense may destroy the essence of the problem:

"complexity and precision bear an inverse relation to one another in the sense that, as the complexity of a problem increases, the possibility of analysing it in precise terms diminishes.” (Zadeh, 1972)

However, although one may point to the problems that ONE causes, one should not be blind to its virtues. The defence of a false theory against a powerful attack on its strong points can generate precisely the environment in which new ideas are generated. Certainly many good ideas are not developed as early as they might be because their originators drop them prematurely, only to see others re-generate them later and show that superficial weaknesses overlay great strength. Defending weak positions is often infinitely more rewarding than buttressing up strong ones. As Kenneth Boulding (1964) has noted, in system theory one must be "willing to make a fool of oneself".

In the search for models of reality, ONE has its virtues. Even if we are dis-satisfied with all existent theories and prepared to defend none, it is the belief that there is ONE that keeps us looking. Unified field theory for gravitational and electromagnetic forces, an organic basis for schizophrenia, controlled energy from thermonuclear reactions, and so on, are all of them unsolved problems, but the belief that a solution exists has made them inspirations for major fields of endeavour and achievement.

In global modeling it is an act of faith that the socio-economic infrastructure has a rationale that can be modeled and a coherence that can be projected into the future. The artefacts inherent in ONE existence phenomena are widely recognized, however, and the modeling presuppositions and different axiological bases for the different schools of global modeling have been extensively documented:

"Here are some other acts of faith that regularly appear in global models of both the mathematical and mental kinds:

1. The poor nations of the world are developing in the same pattern as the Western industrialized nations, but after a time lag.

2. Political leaders are above the global system, outside it, making the important decisions affecting it, and not affected by it.

3. The most important phenomena in the world are economic and can be described in monetary units." (Meadows et al., 1982, p.285) 


\section{MANY: THERE IS AN INDEFINITE VARIETY OF METHODS OF REALITY}

"To believe in the one or in the many, that is the classification with the maximum number of consequences." (James, 1975, p.64, orig. 1907)

"The only principle that does not inhibit progress is: anything goes." (Feyerabend, 1975, p.23)(

The pluralist hypothesis is that which best summarizes actual modeling practice. The decisions to be made are usually highly over-determined and skill in practical modeling comes from the ability to balance and make most effective use of a variety of different bases. This is not necessarily a problem of multiple criteria, but most often one of multiple information sources each of which, in theory, provides sufficient information for modeling.

A good example of this is the long-standing controversy over distance perception (Gibson, 1950): What are the cues that people use in determining the distance of an object? Experimenter $\mathrm{X}$ claims that phenomenon $\mathrm{A}$ is the prime determinant and demonstrates this by removing all cues but A. Sure enough distance perception remains and is highly accurate. Experimenter $\mathrm{Y}$ claims that phenomenon B is the prime determinant and demonstrates this by removing all cues but B. Sure enough distance perception remains and is highly accurate. Sooner or later, after the most refined experimental designs to ensure that no cues of type $\mathrm{B}$ are slipping in to confound those of type A, or vice versa, it is realized that not only are A and B each individually completely adequate distance cues, but the people subconsciously switch from one to another depending on which is available. At this point the excitement of controversy dies down, perhaps even the scientific research (the ONE hypothesis is highly important as a social dynamic), and a few patient researchers are left determining all the different, interchangeable, bases for distance perception.

William James saw pluralism as a healthy tough-minded approach and a key variable in philosophical positions. In recent years Gellner's (1974) promotion of egalitarianism amongst all processes for the Legitimation of Belief, and Feyerabend's (1975) promotion of scientific anarchism in Against Method have been the most robust arguments for pluralism in both principle and practice. Some of the precepts are:

"Science is an essentially anarchistic enterprise: theoretical anarchism is more humanitarian and more likely to encourage progress than its law-and-order alternatives." (Feyerabend, 1975, p.17)

"Proliferation of theories is beneficial for science, whilst uniformity impairs its critical power." (p.35)

"Facts are constituted by older ideologies, and a clash between facts and theories may be a proof of progress.” (p.56)

The real problem, once a pluralist basis for some aspect of practical modeling is found, it to determine how the many different bases are brought together to determine a single model when more than one is available, i.e. how is over-determination resolved? This is a difficult point which is often missed. MANY seems to lack the dialectical strength of both ZERO and ONE because it allows for all possibilities and hence does not bring them into essential conflict. In terms of explanation this may be so. Your explanation is consistent and adequate, so is mine. We are both good fellows who do not need to fight but can revel in mutual self-satisfaction. However, in terms of explanation even, a meta-problem immediately arises as to how two explanations can account for a single phenomenon. Are they ordered in that one can be derived 
from the other, but not vice versa? Are they unrelated, in which case is there a deeper underlying explanation from which both may be derived? One of the rules of the scientific game is that, like acausality, plurality is not allowed except as a matter of short-term expediency.

In terms of the natural world, there is no rule of the game that says that a plurality of bases is not allowed. Moreover, there is no rule either that says that these bases cannot conflict. Generally they do. Over-determination in a precise theory leads to multiple values for essentially singlevalued variables and hence conflict, paradox, and, if the rules of the theory are precisely applied, a total breakdown of the basis for modeling. In distance perception the possibility of such conflicts between the multiple bases of perception leads to optical illusions (Gregory, 1970). The related phenomenon of reasoning illusions in practical reasoning is neglected in work on formal logic because the classical predicate calculus has the theorem:

$$
\square P, Q P \square \bar{P} \quad Q
$$

i.e., that a breakdown of the law of contradiction may be used to derive any conclusion, and hence there is nothing that can be usefully said about this (in the same way that nothing can be said about existence). However, in practical reasoning we seem able to avoid the Wittgensteinian trap of knowing all the consequences of our premises - by using a more appropriate logic rather than just by not working out all possibilities (Gaines, 1979b; Rescher and Brandom, 1980) — and the mechanisms for conflict resolution are a key component of our systems of practical reasoning.

Thus MANY does have its own means of generating dialectical conflict and it is the most subtle and important of all. We have to accept as a basis for practical reasoning that multiple accounts of equal standing will arise and can be in conflict. Decision-making under uncertainty is usually seen as leading to under-determination, but in practice it most often leads to over-determination. Conflict because we are over-provided with information is far more prevalent than other sources of uncertainty where we have too little.

The variety of different global models now available, with different results based on differing presuppositions and value systems may seem confusing to those who wish to use them. However, this variety is an important lesson in itself:

"Perhaps one of the greatest lessons to be learned as the number of global models increases is how human beings from various parts of the globe see the world differently and how they see it commonly." (Meadows et al., 1982, p.103)

\section{CHOICE IN THE FOUNDATIONS OF MODELING}

"All testing, all confirmation and disconfirmation of a hypothesis takes place already within a system. And this system is not a more or less arbitrary and doubtful point of departure for all our arguments; no, it belongs to the essence of what we call an argument. The system is not so much the point of departure, as the element in which arguments have their life." (Wittgenstein, 1969, sect.105, orig.1950)

"cybernetics is the science or the art of manipulating defensible metaphors; showing how they may be constructed and what can be inferred as a result of their existence.” (Pask, 1975, p.13)

The foundations of modeling have been dramatized here because they are worthy of it. If we are unaware of the seething conflicts below any theories, methodologies and practical schemes that we erect then we are not only guilty of that false peace of mind that stems from ignorance, but 
we are also missing out on that major element of choice that comes through conflict. If there are different pre-suppositions possible even at a truly foundational level, all of which are of equal merit (in the sense that they can be defended one against the other), then we have freedom of action in moving between them. It is our choice to be sceptical, to defend a unifying theory, to give equal status to mutually contradictory schemes.

The realization of the extent of choice enables them to be taken lightly. Practical modeling is sometimes a game against nature but most often a game against other modelers, and real games are most often won by changing the rules. Even in the hot-war against nature itself, the rules under which we play are of our own contrivance. It was the decision to consider the impossible concept of action-at-a-distance that enabled Isaac Newton to forecast the motions of apples and planets. It was the decision to place Ernst Mach's eyes in the impossible vehicle of a photon that forced Albert Einstein to distort the certain constancies of space. If this seems more a prescription for rhetoric than for modeling-science then so be it. If rhetoric were not so neglected a science the powerful analogy by which the whole of science is seen as the persuasion of nature would be more often used. In modeling this becomes more than an analogy because it is the persuasion of the world through action that is the key to our success.

In summary, these sections have pointed to two key dialectical conflicts in the foundations of modeling. In terms of the form of argument outlined in (i) to (v) above, there is first a conflict over step (i), existence: the Gorgian sceptic denies it; the ONE and MANY hypotheses both affirm it; the Pyrrhonian sceptic transcends all of them by suspending judgement. Secondly, the ONE and MANY hypotheses themselves come into conflict over step (iv), unicity. This is the classic conflict between the tendency to unify and that to split apart.

In any system of modeling that we build, both of these dialectical possibilities will be present, and in good systems they will be explicitly stated. The greater the awareness that we have of them, the more control we have over the possible choices they give, the more versatile and powerful the modeling system will be. The less we are aware of them, the more likely we are to ascribe valuable differences in approach to incompatible differences in content, and to fail to take advantage of multiple perspectives. As Meadows remarks:

"the single worst problem in the field of modeling at present is the inexperience of modelers in examining their own assumptions, realizing their lack of objectivity, and understanding the relative strengths and weaknesses of their methods." (Meadows et al., 1982, p.217)

\section{THE COMPUTER IN WORLD 3}

"By great good fortune, and just in time, we have to hand a device that can rescue us from the mass of complexity. That device is the computer. The computer will be to the organisation revolution what steam power was to the industrial revolution. The computer can extend our organising power in the same way as steam extended muscle power..... Of course we have to ensure that the result is more human rather than less human. Similarly we have to use the computer to reduce complexity rather than to increase complexity, by making it possible to cope with increased complexity." (De Bono, 1979, p.18)

If we accept that many of the problems of global modeling reduce to those ontological, epistemological and axiological problems that have concerned philosophers for some thousands of years, then we have to ask "what is new?". The sources of novelty in our current situation seem to be twofold and related: firstly that population growth has forced the socio-economic 
world to become florid with complexity, a tightly interlinked network of dependencies; and secondly that we have the computer in this present era as a mind-tool with which to extend ourselves to investigate this complexity. If Plato had been able to program the dynamics of the Republic on a personal computer then we might all still be citizens of that state under an algorithmic philosopher-king!

However, is the computer really a significant new methodological factor, and, if so, how can we bring its role into the debate? We can view the problem of model realism as one of linking abstract theories with concrete phenomena through the mechanism of our minds. The scientific tools of the past have been vehicles for exploring the phenomena of the physical world in greater detail and with greater precision; of opening up a channel between the physical world and that of our minds. The computer as a system for data acquisition, processing and control enhances these tools and widens that channel. However, it also has a quite different role as a system for simulation and model exploration; of opening up a channel between the modeling world and that of our minds.

This view of the computer as providing a vehicle for the exploration of the world of our models (Gaines, 1979a) may be formalized through Popper's (1968) notion of 3 worlds. In his autobiography he introduces it by quoting Bolzano's notion of "truths in themselves" in contradistinction to "those thought processes by which a man may...grasp truths", proposing that:

"thoughts in the sense of contents or statements in themselves and thoughts in the sense of thought processes belong to two entirely different 'worlds'." (Popper, 1974, p.143)

and making the three-fold distinction:

"If we call the world of 'things'-of physical objects-the first world and the world of subjective experience the second world we may call the world of statements in themselves the third world (...world 3).” (p.144)

Popper notes:

"I regard books and journals and letters as typically third-world objects, especially if they develop and discuss a theory." (p.145)

and stresses the key role of world 3 in the development of human civilisation, giving two gedanken experiments on the destruction of civilization to illustrate the status of world 3 -- if:

“(1) all machines and tools are destroyed, also all our memories of science and technology, including our subjective knowledge of machines and tools, and how to use them. But libraries and our capacity to learn from them survive...our world civilization may be restored...from the World 3 that survives"

"(2) in addition all libraries are destroyed ...men would be reduced to the barbarism of primitive man in early prehistory, and civilization could be restored only by the same slow and painful process that has characterized the story of man through Paleolithic times" (Popper, 1968, p.334)

Popper emphasizes the distinct ontological status of world 3:

"I regard the third world as being essentially the product of the human mind. It is we who create thirdworld objects. That these objects have their own inherent or autonomous laws which create unintended and unforeseeable consequences is only an instance (although a very interesting one) of a more general rule, the rule that all our actions have such consequences." (Popper, 1974, p.148)

The computer provides a new dynamic for world 3 just as did the harnessing of energy in world 1 (Gaines, 1979a). It brings world 3 into the demesne of man just as did the steam, internal 
combustion, and jet engines, do for world 1. That is we can move about in, conquer, control and fabricate to our needs the lands and materials of world 3 using computers in a way that makes our previous efforts, all but a few, look feeble. Those few we shall look back upon in wonder as we do the construction in world 1 of the Egyptian pyramids, equalled in world 3 by Greek philosophy. However, such impossible achievements prior to the harnessing of inhuman energy and inhuman intellect will be surpassed in achievement, if not in wonder, through our control of mechanisms that give us control of the worlds in which they exist: the energetic engines of world 1 and the informatic engines of world 3.

The role of computers in world 3 can be seen most clearly by contrasting information within a library with that in a computer database. The library itself is passive, waiting for scholars and technicians to tap its stored information, but powerless to process that information in any way, to classify it, extend it, and correlate it, except through human mediation. The database contains the same information as the library but may also itself be active through processes that interact with that information without necessary human mediation, sifting through the stored data structures, analysing and comparing information, and building new structures to enhance and extend those already present.

The library is like a museum of preserved flowers, a static record of unchanging knowledge, whereas the database can be a living garden subject to growth and evolution, changing even as we study it. Less poetically, an active database system incorporating a complete library is the closest structure to a global model of all there is. Research on inference-based knowledge structures in fifth generation computing systems (Moto-oka, 1982) is making the first steps in this direction but we still have a long way to go before the potential of such a database begins to be realized.

In case our enthusiasm for computers and world 3 becomes too great it is worth quoting some alternative viewpoints:

"the reification of abstract phenomena can be interpreted in psychiatric terms as schizophrenia, that is, as a kind of logical disease in which man constructs an abstract world but treats it as if it were real and concrete." (Zijderveld, 1970, p.51)

The independence of these remarks of modern technology is clear in the remarks of a rather earlier writer:

"Leave us to ourselves, without our books, and at once we get into a muddle and lose our way - we don't know whose side to be on or where to give our allegiance, what to love and what to hate, what to respect and what to despise. We even find it difficult to be human beings... and are always striving to be some unprecedented kind of generalized human being...Soon we shall invent a method of being born from an idea." (Dostoyevsky, 1864, p.123)

And the father of modern computer and communication technology warned us of its potential for abuse:

"the motive which the gadget worshipper finds for his admiration of the machine...is the desire to avoid personal responsibility for a dangerous or disastrous decision by placing the responsibility elsewhere: on chance, on human superiors and their policies which one cannot question, or on a mechanical device which one cannot fully understand but which has a presumed objectivity." (Wiener, 1964, p.59-60) 
Certainly in global modeling with large and complex systems of equations having their own existence within a computer we can easily be guilty of any of these. However, the literature shows a high awareness of just such problems and the warnings are already part of it:

"Computer modeling techniques are also based on deep, unexpressed, technical paradigmatic assumptions that are not congruent with mental models and often constrain what can be included." (Meadows et al., 1982, p.12)

What comes out of the model of the computer as a vehicle to explore world 3 is a more subtle criticism of our modeling to date. Namely that this very interactive exploration of our model spaces is just what is missing. We cannot through computer printouts, even in graphical form, get that essential gut-feel for our simulations that comes only in traversing them interactively. We have to project ourselves into the computer and become aware of the interplays involved by varying conditions and riding the waves thus created. This will involve fast simulation, effective multi-modal information presentation, and the ability to play within our models freely and understandably. We should also be able to take others along with us on these voyages so that there is mutual understanding of the phenomena involved and the development of new shared meanings. It is this free exploratory conversational interaction with computers that makes the relationship emancipatory cognitive rather than technical cognitive (Habermas, 1968).

\section{SYSTEMIC FOUNDATIONS FOR 3 WORLDS}

"I have been considering whether anything in the world exists, and have observed from the very fact that I examine the question it necessarily follows that I do exist.” (Descartes, 1964, p.145, orig. 1642)

"a universe comes into being when a space is severed or taken apart...The act is itself already remembered, even if unconsciously, as our first attempt to distinguish different things in a world where, in the first place, the boundaries can be drawn anywhere we please. At this stage the universe cannot be distinguished from how we act upon it, and the world may seem like shifting sand beneath our feet...Although all forms, and thus all universes, are possible, and any particular form is mutable, it becomes evident that the laws relating such forms are the same in any universe". (Brown, 1969, p.v)

The notion of 3 worlds is attractive in giving us a framework in which to explore model realism, the role of ourselves and the role of the computer. It may be given systemic foundations by adopting the ONE position defined previously and defining Popper's 3 worlds by minimal distinctions necessary to generate them (Gaines and Shaw, 1983). This, as is usual with ONE, leads a number of steps of reasoning that are blatantly fallacious by certain criteria. However, from an overall position that is based on MANY and conventionalistic, each of these false/true steps is a bifurcation generating various flavors of philosophy. ONE always skates over a great deal of very thin ice; the choice of where to fall in is part of the argument.

The fundamental postulate is that:

FP There exists distinction-making, some necessary.

This traps us (through ontological fallacies) into:

W3 There exist distinctions - world 3

W2 There exist distinction makers-world 2

W1 There exists a source for necessary distinctions-world 1 
The worlds arise through a similar chain of reasoning that since something exists it must exist somewhere. To term them all worlds hides a category error that undoes much of the beautiful analyses of Kant, Hegel and Peirce. However, the choice is open: "to refuse to allow a distinction is also a meaningful action...It does not allow changes in oneself, the world and others" (Gaines and Shaw, 1981).

It is useful to flatten the categories for the moment, and regard them as all being at the same level.

What we have at the end of this chain of 'reasoning' is a systemic framework for the three worlds. It is capable of being re-organized to match any metaphysical foundations. For example, the Cartesian argument doubts all, intuits FP through desperation, derives W2 first through egocentricity, then gets W3 from what is thought and W1 from what is "am". The Hegelian problem is to justify FP; that need not be done for the purposes of this paper, or for the purposes of global modeling.

This definition of the three worlds through generative distinctions has proved useful in analysing a range of philosophical, theological, psychological and physical arguments. For example, the ascription of reality to necessity in defining world 1 goes back to the notion of the real world as that of absolute essences. However, in psychological terms it models the reification of that which we take to be necessary, phenomena outside our minds and beyond our choice. Accepted dogma that controls our actions becomes as much part of the physical world as gravity. We bump into a wall and it hurts us. We bump into a superordinate moral imperative and it hurts us. We cannot see through the wall but neither can we see through our own missing constructs.

Thus our systemic model of 3 worlds encompasses the distinctions which Popper makes and gives new insight into the different interpretations possible for reality. In particular it enables us to account for the variety of criteria of necessity that people lump together in thinking about reality. Empirical testing is by no means the only test of scientific reality, and is itself open to the criticism of being theory-laden (Kordig, 1971). We need the untestable pre-suppositions of our ideologies to get started in our modeling, and even what is meant to be testable may not be in practice. Much of reality is validated by not being tested or by being tested in such a way that it cannot fail to be validated. As global modelers:

"We are not eager to put our hypotheses to stringent tests against the real world. We are only rewarded for being right. We are laughed at for being wrong. So we design our tests and select our results to maximize the possibility of being right." (Meadows et al., 1982, p.286)

\section{SOME EXPLORATION OF 3 WORLDS}

"Knowledge is an attitude, a passion. Actually an illicit attitude. For the compulsion to know is a mania, just like dipsomania, erotomania, homicidal mania: it produces a character out of balance. It is not at all true that a scientist goes after truth. It goes after him. It is something he suffers from." (Judson, 1979, p.97, attributed to Kierkegaard by Wilkins)

“THROUGH ME THE WAY INTO THE WOEFUL CITY.

THROUGH ME THE WAY TO THE ETERNAL PAIN.

THROUGH ME THE WAY AMONG THE LOST PEOPLE.

...ABANDON EVERY HOPE, YE THAT ENTER.” (Dante, 1948, Canto III, orig.c.1300) 


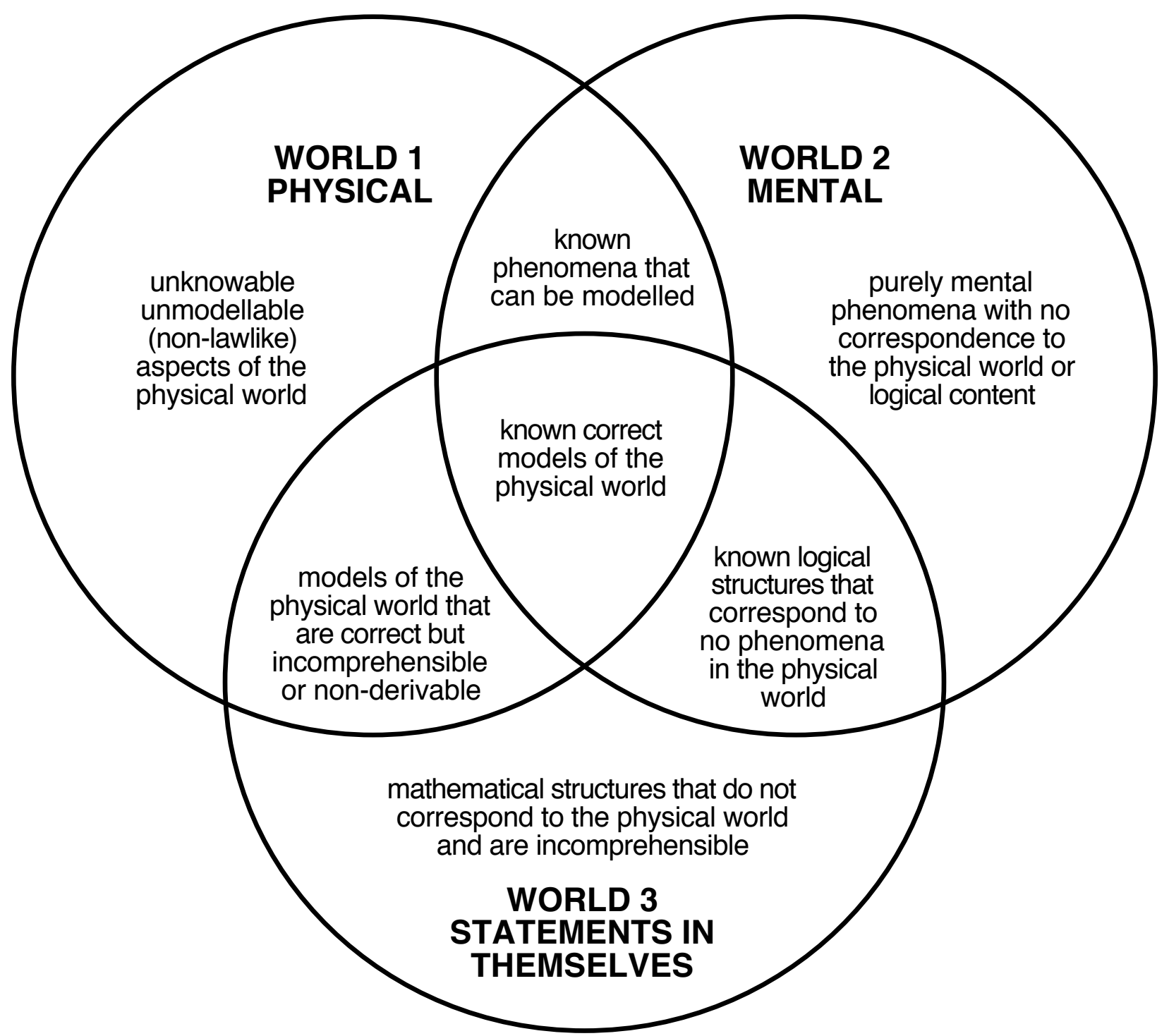

Figure 1 Paradise, purgatory and hell in Popper's 3 worlds

It is now possible to attempt a grand synthesis with the material at our disposal and set up a superordinate model of the board on which we play our game of life. Fig. 1 shows Popper's 3 worlds as a Venn diagram in which the key aspects of the modeling debate relate to the dynamics of motion between the seven areas of intersection in this diagram. For clarity these areas are labelled in a blatantly simple-minded way which takes world 1 to be reality, world 3 to contain models of it and world 2 to contain the mediating processes whereby we both experience reality and comprehend models of it.

The central region where all three worlds intersect is that of models in world 3 that are known because they are in world 2 and correct because they correspond to the reality of world 1 . This is the target region for our game and we aim to position our scientific persona in this region. This 
region is so sanctified by science that it deserves a truly glorious name and we may call it paradise.

The three intersections of two worlds outside this region each have interesting characteristics. Where world 1 intersects world 2 outside paradise is the domain of phenomena that can be experienced and known but not modeled. It encompasses the paranormal, luck, intuition, synchronicity and possibly some of the central dynamics of human existence such as agape and altruism. Where world 2 intersects world 3 outside paradise is the domain of formal structures that we can understand but correspond to no phenomena in world 1. It encompasses much pure mathematics but also art forms, myths, religions and cultural norms. Where world 3 intersects world 1 outside paradise is the domain of models of reality that are beyond our comprehension. It encompasses unified field theory and complete global models (unless both are myths properly belonging to the intersection of world 2 and world 3). In naming these regions we should take account their transitory nature as way stations to paradise and see them as different forms of purgatory.

Most fascinating of all are those parts of the 3 worlds that intersect no others. World 1 outside purgatory and paradise is that of physical phenomena which cannot be experienced and cannot be modeled -- some $99.9999 . . \% \%$ of the physical world. World 2 outside purgatory and paradise is that of mental events with no correspondence to reality and no logical content -- some $99.9999 . . . \%$ of our mental lives. World 3 outside purgatory and paradise is that of formal structures that are beyond the limits of our understanding and violate any correspondence principle -- some $99.9999 . . \% \%$ of theorems that most axiom systems will generate. Such is the nature of hell.

Philosophies of science are concerned with the rules that define where a system of statements lies in this diagram. The positivists were concerned to restrict access to paradise to that which could meet very rigid entry conditions:

"We say that a sentence is factually significant to any given person, if, and only if, he knows how to verify the proposition which it purports to express -- that is, if he knows what observations would lead him, under certain conditions, to accept the proposition as being true, or reject it as being false." (Ayer, 1936, p.35)

The confirmationists allowed a creeping in or out of paradise as evidence built up for good or bad standing:

"A sentence is regarded as confirmable if observation sentences can contribute either positively or negatively to its confirmation." (Carnap, 1963, p.59)

The falsificationists on the other hand had an easy going entry policy and concentrated on bouncing out those that proved unworthy, indeed they welcomed the most unlikely candidates as those most easy to throw out:

"The best hypothesis, in the sense of one most recommending itself to the enquirer, is the one which can be most readily refuted if it is false. This far outweighs the trifling merit of being likely. For after all, what is a likely hypothesis? It is one that falls in with our preconceived ideas." (Peirce, 1958, orig.c.1900)

As scientists and global modelers we may all be seen as redemptionists searching through the three different forms of purgatory for candidates for paradise. One style is to attempt to drag the intersection of worlds 3 and 1 into world 2 by advancing our own comprehension. Another is to 
assume that the there must exist rationales in world 3 for the phenomena in the intersection of worlds 1 and 2. Another is to search world 1 for phenomena corresponding to structures in the intersection of worlds 2 and 3. It is a significant question in evaluating any modeling school as to which approach, or mixture of approaches they are adopting. The existence presuppositions and corresponding artefacts are quite different:

"The global model you have decided you like best may tell you not so much about the world as about yourself." (Meadows et al., 1982, p.106)

\section{CONCLUSIONS}

"Time present and time past

Are both perhaps present in time future,

And time future contained in time past.

If all time is eternally present

All time is unredeemable.

What might have been is an abstraction

Remaining a perpetual possibility

Only in world of speculation.” (Eliot, 1959, p.13)

This paper has emphasized the many-faceted nature of reality and the choices that we have, that we are forced to make, before we can speak of model realism. One choice that has already been made by humankind is that we are not to be passive observers of reality but active participants in its development and change. Our technology has developed to a stage where our interference with natural reality is a major force for the future. Our improved models and powerful technologies give us increasing knowledge of reality and increasing power to change it. One message of global modeling has been that some highly possible futures held no place for people, largely through the actions of humankind (Peccei, 1981).

That is one of our choices, one of our distinctions, one of the value judgements we must make, whether to survive or not. Taking a ONE position and postulating our own existence in all possible futures is inherent in our natures but fallacious. Taking a similar position as a nation or as an individual and postulating our own supreme importance seems equally inherent in our natures yet equally fallacious. As we come to model all there is we are finding that the choices of today determine all there may be tomorrow, and that many "obvious" choices that have served us well in the past have become inappropriate for the future.

Chris Evans advanced the argument that computer modeling of future scenarios in war games had been a major force in preventing world war 3, that human military experts when faced with the possibility of war are prone to assume that they can commence battle and win, but:

"when the same statistics are fed into the computer's unemotional, apolitical interior, what comes out is as true and objective an appraisal as can be made from the facts. Furthermore, whenever the data involves confrontation between nuclear powers, the unequivocal message that spills out-to both sides-is: You will lose!" (Evans, 1981, p.212)

This argument involves great faith in both model realism and in human rationality but its logic is at the heart of most global modeling, that if we can project the implications of the present into the future then we can change our behavior to at least avoid the worst possible worlds. 
Finally, at the end of a paper which is evidence for Goethe's remark that academics are just like dogs cocking their legs and dropping quotations on every possible occasion (Luke and Pick, 1966, p.186), let us end with a triply embedded quotation on the inevitability of our quest to model all there is. Evans quotes Korda's film of H.G.Wells Things to Come:

"there can be no rest, for once Man has taken the first step down the path of knowledge and understanding, he must take all those that follow. The alternative is to do nothing, to live with the insects in the dust. The choice is simple - it is the whole universe, or nothing." (Evans, 1981, p.245)

\section{ACKNOWLEDGEMENTS}

I am grateful to Susan Haack and Gordon Pask for their comments on an earlier draft of this paper; to Horst Wedde for giving me the opportunity to present it at Bad Honnef; to the referees for their stimulating comments; and to Mildred Shaw for her criticism of earlier drafts.

\section{REFERENCES}

Ayer, A.J. (1936). Language, Truth and Logic. London, Victor Gollancz.

Berkeley, G. (1710). The Principles of Human Knowledge. London, Collins.

Boulding, K. (1964). General systems as a point of view. Mesarovic, M.D., Ed. Views on General Systems Theory. pp.25-38. New York, John Wiley.

Bremmermann, H.J., Rogson, M. and Salaff, S. (1965). Search by evolution. Maxfield, M., Callahan, A. and Fogel, L.J., Ed. Biophysics and Cybernetic Systems. pp.157-167. Washington D.C., Spartan Books.

Brown, G.S. (1969). Laws of Form. London, George Allen \& Unwin.

Carnap, R. (1963). Intellectual Autobiography. P.A.Schilpp, Ed. The Philosophy of Rudolf Carnap. La Salle, Illinois, Open Court.

Catalano, J.S. (1974). A Commentary on Jean-Paul Sartre's "Being and Nothingness". New York, Harper \& Row.

Dante, A. (1948). The Divine Comedy. London, Bodley Head.

De Bono, E. (1979). Future Positive. London, M. Temple Smith.

Descartes, R. (1964). Philosophical Writings. London, Nelson.

Dostoyevsky, F. (1864). Notes from the Underground. Middlesex, UK, Penguin.

Eliot, T.S. (1959). Four Quartets. London, Faber \& Faber.

Evans, C. (1981). The Micro Millennium. New York, Washington Square Press.

Feyerabend, P., Ed. (1975). Against Method. London, NLB.

Gaines, B.R. (1977). System identification, approximation and complexity. International Journal of General Systems 2(3) 241-258.

Gaines, B.R. (1978). General system identification-fundamentals and results. Klir, G.J., Ed. Applied General Systems Research. pp.91-104. New York, Plenum. 
Gaines, B.R. (1979a). Computers and society: the basis for a systemic model. Ericson, R.F., Ed. Improving the Human Condition: Quality and Stability in Social Systems. pp.523-530. Kentucky, Society for General Systems Research.

Gaines, B.R. (1979b). Logical foundations for database systems. International Journal of ManMachine Studies 11(4) 481-500.

Gaines, B.R. (1980). General systems research: quo vadis? Gaines, B.R., Ed. General Systems 1979. pp.1-9. Kentucky, Society for General Systems Research.

Gaines, B.R. and Shaw, M.L.G. (1981). A programme for the development of a systems methodology of knowledge and action. Reckmeyer, W.J., Ed. General Systems Research and Design: Precursors and Futures. pp.255-264. Louisville, Kentucky, Society for General Systems Research.

Gaines, B.R. and Shaw, M.L.G. (1983). Is there a knowledge environment? Lasker, G.E., Ed. The Relation Between Major World Problems and Systems Learning. pp.27-34. Kentucky, Society for General Systems Research.

Gellner, E., Ed. (1974). Legitimation of Belief. Cambridge, UK, Cambridge University Press.

Gibson, J.J. (1950). The Perception of the Visual World. Boston, Houghton Mifflin.

Goodwin, B. (1978). Social Science and Utopia: Nineteenth-century Models of Social Harmony. Atlantic Highlands, N.J., Humanities Press.

Gregory, R.L. (1970). The Intelligent Eye. London, Weidenfeld \& Nicolson.

Habermas, J. (1968). Knowledge and Human Interests. London, Heinemann.

Hegel, G.W.F. (1816). Science of Logic. London, George Allen \& Unwin.

Hume, D. (1739). A Treatise of Human Nature. Oxford, Clarendon Press.

James, W. (1975). Pragmatism. Cambridge, MA, Harvard University Press.

Jaspers, K. (1931). Man in the Modern Age. London, Routledge \& Kegan Paul.

Judson, H.F. (1979). The Eighth Day of Creation. New York, Simon \& Schuster.

Kant, I. (1781). Critique of Pure Reason. London, George Bell.

Kordig, C.R. (1971). The Justification of Scientific Change. Dordrecht, Reidel.

Kuhn, T.S. (1962). The Structure of Scientific Revolutions. Chicago, University of Chicago Press.

Lenin, V.I. (1961). Conspectus of Hegel's Science of Logic. London, Lawrence \& Wishart.

Luhmann, N. (1979). Trust and Power. Chichester, UK, Wiley.

Luke, D. and Pick, R. (1966). Goethe: Conversations and Encounters. London, Oswald Wolff.

Marcuse, H. (1964). One Dimensional Man: The Ideology of Industrial Society. London, Sphere Books.

Meadows, D.H., Richardson, J. and Bruckmann, G. (1982). Groping in the Dark: The First Decade of Global Modelling. New York, Wiley. 
Mensch, G. (1975). Stalemate in Technology: Innovations Overcome the Depression. Cambridge, Massachusetts, Ballinger.

Moto-oka, T., Ed. (1982). Fifth Generation Computer Systems. Amsterdam, North-Holland.

Pask, G. (1975). The Cybernetics of Human Learning and Performance. London, Hutchinson.

Peccei, A. (1981). One Hundred Pages for the Future: Reflections of the President of the Club of Rome. New York, Pergamon Press.

Peirce, C.S. (1958). Collected Papers I. Massachusetts, Havard University Press.

Plato (1958). The Republic. Baltimore, Penguin Books.

Popper, K.R. (1963). Conjectures and Refutations: The Growth of Scientific Knowledge. London, Routledge \& Kegan Paul.

Popper, K.R. (1968). Epistemology without a knowing subject. Rootselaar, B.V., Ed. Logic, Methodology and Philosophy of Science III. pp.333-373. Amsterdam, North-Holland.

Popper, K.R. (1972). Objective Knowledge: an Evolutionary Approach. Oxford, Clarendon Press.

Popper, K.R. (1974). Autobiography of Karl Popper. Schilpp, P.A., Ed. The Philosophy of Karl Popper. pp.3-181. La Salle, Illinois, Open Court.

Ralescu, D. (1979). A system theoretic view of social identification. Ericson, R.F., Ed. Improving the Human Condition: Quality and Stability in Social Systems. pp.531-538. Louisville, Society for General Systems Research.

Rescher, N. and Brandom, R. (1980). The Logic of Inconsistency: A Study in Non-standard Possible-world Semantics and Ontology. Oxford, Blackwell.

Russell, B. (1946). History of Western Philosophy. London, Allen \& Unwin.

Sartre, J.P. (1943). L'Etre et le Néant. Paris, Gallimard.

Schock, R. (1968). Logics Without Existence Assumptions. Stockholm, Almqvist \& Wiksell.

Schutz, A. and Luckmann, T. (1973). The Structures of the Life-World. London, Heinemann.

Sextus Empiricus (1933). Outlines of Pyrrhonism. London, W. Heinemann.

Shaw, M.L.G. (1980). On Becoming A Personal Scientist: Interactive Computer Elicitation of Personal Models Of The World. London, Academic Press.

Toffler, A. (1970). Future Shock. New York, Random House.

Toffler, A. (1980). The Third Wave. New York, William Morrow.

Unger, P.K. (1975). Ignorance: A Case for Scepticism. Oxford, Clarendon Press.

Wedde, H. (1983). Adequate modeling of Systems: Proceedings of the International Working Conference on Model Realism, held in Bad Honnef, Federal Republic of Germany, April 20-23, 1982. Berlin, Springer-Verlag. 
Wiener, N. (1964). God and Golem, Inc.; A Comment on Certain Points, Where Cybernetics Impinges on Religion. Cambridge, M.I.T. Press.

Wiley, M.L. (1966). Creative Sceptics. London, Allen \& Unwin.

Wittgenstein, L. (1953). Philosophical Investigations. Oxford, Blackwell.

Wittgenstein, L. (1969). On Certainty. Oxford, Basil Blackwell.

Wittgenstein, L. (1972). Tractatus Logico-Philosophicus. London, Routledge \& Kegan Paul.

Zadeh, L.A. (1972). Fuzzy languages and their relation to human intelligence. Proceedings International Conference on Man and Computer. Basel, Karger.

Zijderveld, A.C. (1970). The Abstract Society. London, Allen Lane. 